Jurnal Health Sains: p-ISSN: 2723-4339 e-ISSN: 2548-1398

Vol. 2, No. 3, Maret 2021

\title{
FAKTOR-FAKTOR YANG MEMPENGARUHI KEJADIAN KOMPLIKASI KETUBAN PECAH DINI (KPD) DI RSUD DR MM DUNDA LIMBOTO
}

\author{
Rizky Nikmathul Ali, Fidyawati Aprianti A. Hiola dan Veni Tomayahu
}

Universitas Muhammadiyah Gorontalo, Indonesia

Email: rizkynikmathulali@umgo.ac.id, fidyahiola@umgo.ac.id dan venitomayahu@gmail.com

\begin{tabular}{|c|c|}
\hline ARTIKEL INFO & BSTRACT \\
\hline $\begin{array}{l}\text { Tanggal diterima: } 5 \text { Maret } 2021 \\
\text { Tanggal direvisi: } 15 \text { Maret } 2021 \\
\text { Tanggal disetujui: } 25 \text { Maret } 2021\end{array}$ & $\begin{array}{l}\text { Premature rupture of membranes is very dangerous for } \\
\text { pregnant women and their babies. The danger of } \\
\text { premature rupture of membranes is infection in the }\end{array}$ \\
\hline $\begin{array}{lr}\text { Keywords: } & \\
\text { Premature } \quad \text { Rupture } & \text { of } \\
\text { Membranes; Occupation; Fetal } \\
\text { Abnormality Location; } & \text { Fetal } \\
\text { Weight; Gemeli. } & \end{array}$ & $\begin{array}{l}\text { mother and baby. The research objective was to } \\
\text { determine the factors that cause premature rupture of } \\
\text { membranes }(P R O M) \text {. The populations were all pregnant } \\
\text { women at RSUD MM Dunda Limboto, Gorontalo } \\
\text { Regency, there are } 181 \text { populations. The samples were } \\
38 \text { respondents used purposive sampling technique. } \\
\text { obtained the calculated chi square value }>\text { chi square } \\
\text { table }(4.071>3.841) \text { or } p=0.044<<\alpha \text {, }<\text {, then HO is } \\
\text { rejected, thus it can be concluded that there is a } \\
\text { relationship between the respondent's occupation and } \\
\text { Premature rupture of membranes and OR: } 4.167 \text { means } \\
\text { working mothers during pregnancy have } 4 \text { times the risk } \\
\text { for premature rupture of membranes. It is known that } \\
\text { the chi square value of Fetal Position Abnormalities is } p \\
=0.746>>0.05 \text {, Fetal Weight is } p=0.555>>0.05 \text {, } \\
\text { Gemeli } p=0.721>>\alpha \text {.05 which means that Ho is } \\
\text { accepted, so it can be concluded that there is no } \\
\text { relationship between Fetal Position Abnormalities, BW } \\
\text { fetus, Gemeli with Premature rupture of membranes. } \\
\text { Conclusion is Factors that influence PROM are } \\
\text { occupation and those that do not affect PROM are fetal } \\
\text { location abnormalities, fetal weight, and Gemeli }\end{array}$ \\
\hline
\end{tabular}

\section{ABSTRAK}

Ketuban pecah dini sangat berbahaya bagi ibu hamil maupun bayinya. Bahaya dari ketuban pecah dini adalah infeksi terjadi pada ibu dan bayi. Tujuan penelitian yaitu untuk mengetahui faktor-faktor yang menyebabkan terjadinya ketuban pecah dini (KPD). Metode penelitian yaitu analitik korelasional dengan cross sectional. Populasi dalam penelitian ini adalah seluruh ibu hamil di RSUD MM Dunda Limboto Kabupaten Gorontalo yaitu 181 populasi. Sampel dalam penelitian ini yaitu 38 orang dengan menggunakan tehnik penarikan sampel pusposive sampling. Diketahui nilai chi square hitung $>$ chi square tabel $(4.071>3.841)$ atau $\mathrm{p}=0.044<<\alpha$ 0.05 , maka H0 ditolak, jadi dapat simpulkan bahwa ada hubungan pekerjaan responden dengan Ketuban Pecah 
Kata Kunci:

Ketuban Pecah Dini; Pekerjaan; Letak Kelainan Janin; BB Jani, Gemeli.
Dini (KPD) dan OR: 4.167 artinya ibu yang bekerja selama kehamilan memiliki 4 kali beresiko untuk mengalami ketuban pecah dini. Diketahui nilai chi square pada Kelainan Letak Janin $\mathrm{p}=0.746>>0.05$, BB Janin $\mathrm{p}=0.555>>\alpha 0.05$, Gemeli $\mathrm{p}=0.721>>\alpha 0.05$ yang artinya $\mathrm{HO}$ diterima, jadi dapat simpulkan bahwa tidak ada hubungan Kelainan Letak Janin, BB janin, Gemeli dengan Ketuban Pecah Dini (KPD). Kesimpulan Faktor yang mempengaruhi KPD yaitu pekerjaan dan yang tidak mempengaruhi KPD yaitu Kelainan Letak Janin, BB janin, Gemeli.

\section{Pendahuluan}

Ketuban pecah dini (KPD) adalah robeknya selaput khorioamnion dalam kehamilan atau fase laten persalinan, ketuban pecah dini merupakan penyebab terbesar persalinan prematur dengan berbagai akibatnya. Ketuban pecah dini adalah keadaan dimana melemahnya dinding membran janin atau rupturnya membran amnion dan kohorion kemudian ketuban pecah dan 1 jam kemudian tidak terdapat tanda-tanda awal persalinan yakni bila pembukaan pada primigravida kurang dari 3 $\mathrm{cm}$ dan pada multigravida kurang dari $5 \mathrm{~cm}$, ketuban pecah dini dapat terjadi pada kehamilan <32-34 minggu, kehamilan 32-37 minggu dan kehamilan >37 minggu (Winkjosastro, 2012).

Selaput ketuban yang membatasi rongga amnion terdiri atas amnion dan korion yang sangat erat ikatannya. Lapisan ini terdiri dari beberapa sel seperti, sel epitel, sel mesenkim, sel trofoblas yang terikat erat dalam matriks kolagen. Selaput ketuban berfungsi menghasilkan air ketuban yang melindungi janin terhadap infeksi. Dalam keadaan normal selaput ketuban pecah dalam proses persalinan bila ketuban pecah dini terjadi sebelum usia 37 minggu disebut ketuban pecah dini pada kehamilan
Coresponden Author:

Email: rizkynikmathulali@umgo.ac.id Artikel dengan akses terbuka dibawah lisensi

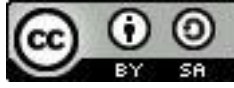

premature. Dalam keadaan normal 8-10\% perempuan hamil aterm akan mengalami ketuban pecah dini (Prawirohardjo, S. \& Wiknjosastro, 2014).

Ketuban pecah dini merupakan komplikasi yang berhubungan dengan kehamilan kurang bulan, dan mempunyai kontribusi yang besar pada angka kematian perinatal pada bayi yang kurang bulan. Pengelolaan KPD pada kehamilan kurang dari 34 minggu sangat kompleks, bertujuan untuk menghilangkan kemungkinan terjadinya prematuritas dan RDS (Respiration Dystress Syndrome) (Demiarti \& Utami, 2017).

Komplikasi ketuban pecah dini yang paling sering terjadi pada ibu bersalin yaitu infeksi dalam persalinan, infeksi masa nifas, partus lama, perdarahan postpartum, meningkatkan kasus bedah sesar, serta meningkatkan mordibitas dan mortilitas maternal. Penyebab terjadinya ketuban pecah dini belum diketahui secara pasti, kemungkinan faktor predisposisi seperti infeksi, kelainan letak janin, gemeli, hidramnion dan anemialah yang menjadi faktor utama dalam kejadian ketuban pecah dini (Huda et al., 2013).

Menurut (Legawati, 2018) dampak KPD pada janin dapat menyebabkan 
berbagai macam komplikasi neonatus meliputi prematuritas, respiratory distress syndrome, pendarahan intraventrikel, sepsis, hipoplasia paru, deformitas skeletal sehingga mengakibatkan gawat janin, sedangkan dampak ketuban pecah dini pada ibu dapat menyebabkan hubungan langsung dengan dunia luar dan ruangan dalam rahim, sehingga memudahkan terjadinya infeksi asenden dan infeksi intrapartal (Legawati, 2018). Selain itu juga dapat dijumpai infeksi puerpuralis (nifas), peritonitis, dan septisemia, serta dry-labor. Makin lama periode laten, makin besar kemungkinan infeksi dalam rahim, persalinan prematuritas dan selanjutnya meningkatkan kejadian kesakitan dan kematian ibu dan bayi atau janin dalam rahim (Prastuti, 2016).

Penanganan KPD terdapat pada kebijakan pemerintah dalam Permenkes Nomor 369/Menkes/SK/III/2007 tentang standar profesi bidan yang terdapat pada kompetensi ke-3 tentang asuhan dan konseling selama kehamilan yaitu bidan memberi asuhan antenatal bermutu tinggi untuk mengoptimalkan kesehatan selama kehamilan yang meliputi deteksi dini, pengobatan atau rujukan dari komplikasi tertentu. Dalam hal ini bidan harus mampu memberikan pelayanan kesehatan seoptimal mungkin dengan melakukan deteksi dini untuk meminimalisir terjadinya komplikasi yang akan terjadi sehingga dapat mengurangi angka kematian ibu salah satunya adalah kejadian ketuban pecah dini.

Berdasarkan penelitian yang dilakukan oleh (Puspitasari, 2019) yang berjudul korelasi karakteristik dengan penyebab ketuban pecah dini pada ibu bersalin didapatkan hasil faktor penyebab ketuban pecah dini dalam penelitian ini meliputi : serviks inkompeten, overdistensi uterus, kelainan letak, CPD, dan infeksi. Umur ibu berkorelasi dengan kejadian serviks inkompeten, CPD, dan Infeksi, sedangkan pekerjaan ibu berhubungan dengan kelainan letak (Puspitasari, 2019).

Allah Subhana Wata'ala berfirman dalam surat Al-Mu'minun ayat 12-14: "Dan sesungguhnya kami telah menciptakan manusia dari suatu saripati (berasal) dari tanah. Kemudian kami jadikan sari patih itu air mani (yang disimpan) dalam tempat yang kokoh (rahim). Kemudian air mani itu kami jadikan segumpal darah, lalu segumpal darah itu kami jadikan segumpal daging dan segumpal daging itu kami jadikan tulang belulang, lalu tulang belulang itu kami bungkus dengan daging. Kemudian kami jadikan dia mahluk yang (berbentuk) lain. Maha suci Allah, pencipta yang paling baik".

Menurut data dari World Health Organization (WHO) tahun 2014 kejadian ketuban pecah dini atau insiden PROM (prelobour rupture of memberane) berkisar antara 5-10\% dari semua kelahiran. KPD preteterm $1 \%$ dari semua kehamilan dan $70 \%$ kasus KPD terjadi pada kehamilan aterm. Pada 30\% kasus KPD merupakan penyebab kelahiran premature. Menurut WHO angka kejadian ketuban pecah dini di dunia mencapai $12,3 \%$ dari total persalinan, semuanya tersebar di Negara berkembang di Asia Tenggara seperti Malaysia, Myanmar, Thailand dan Indonesia.

Menurut Dinas Kesehatan RI penyebab AKI dan AKB yaitu perdarahan, infeksi hipertensi, dan abortus. Infeksi dan perdarahan merupakan komplikasi dari ketuban pecah dini. Di Indonesia ketuban pecah dini berkisar 4,4-7,6\% dari seluruh kehamilan. Angka kejadian ketuban pecah dini berkisar antara 3-18\% yang terjadi pada kehamilan preterm, sedangkan pada kehamilan aterm 8-10\% (Riskesdas, 2016).

Data dari Dinas Kesehatan kabupaten Gorontalo jumlah ibu hamil 1 tahun terkahir sebanyak 7665 ibu, sedangkan persalinan dengan indikasi ketuban pecah dini dari bulan Januari sampai dengan Desember pada tahun 2019 sebanyak 7.381 ketuban pecah dini 
(Dikes, Kabupaten Gorontalo, 2019). Data dari rumah sakit MM Dunda Limboto didapatkan ibu hamil dengan indikasi ketuban pecah dini dari bulan Januari sampai Desember 2019 sebanyak 181 kejadian KPD.

\section{Metode Penelitian}

Penelitian ini dilaksanakan pada bulan September 2020 di RSUD MM Dunda Limboto. Peneliti mengambil lokasi ini karena data KPD terbanyak ada di RSUD MM Dunda Limboto.

Desain penelitian yang digunakan survei analitik dengan menggunakan pendekatan retrospektif yaitu dengan menggunakan data yang sudah terkumpul sebelumnya sehingga peneliti tidak perlu lagi melaksanakan pengumpulan data selama periode selanjutnya (Lapau, 2012).

Desain yang digunakan pada penelitian ini untuk mengetahui faktor-faktor variabel independen yaitu kelaian letak janin, gemeli, pekerjaan, berat janin yang mempengaruhi variabel dependen yaitu ketuban pecah dini.

\section{Hasil dan Pembahasan}

Tabel 1

Jumlah Pegawai Dokter, Perawat Dan Kebidanan

\begin{tabular}{|c|c|c|c|c|c|}
\hline No & $\begin{array}{c}\text { Tenaga medis } \\
\text { rumas sakit } \\
\text { Tahun } 2019 \\
\end{array}$ & PNS & $\begin{array}{c}\text { Kontr } \\
\text { ak }\end{array}$ & $\begin{array}{c}\text { Abd } \\
\mathbf{i}\end{array}$ & $\begin{array}{c}\text { Paru } \\
\text { waktu }\end{array}$ \\
\hline \multirow[t]{9}{*}{1} & Tenaga Dokter & & & & \\
\hline & Dokter umum & 16 & 5 & & \\
\hline & Dokter gigi & 2 & & & \\
\hline & $\begin{array}{l}\text { Pelayanan } \\
\text { medik spesialis } \\
\text { dasar }\end{array}$ & 6 & 3 & & \\
\hline & $\begin{array}{l}\text { Pelayanan } \\
\text { medik spesialis } \\
\text { penunjang }\end{array}$ & 2 & 1 & 2 & \\
\hline & $\begin{array}{l}\text { Pelayanan } \\
\text { medik spesialis } \\
\text { lain }\end{array}$ & 7 & 1 & & 3 \\
\hline & $\begin{array}{l}\text { Pelayanan } \\
\text { medik spesialis } \\
\text { gigi dan mulut }\end{array}$ & 1 & 2 & & \\
\hline & $\begin{array}{l}\text { Pelayanan } \\
\text { medik spesialis } \\
\text { lain }\end{array}$ & & & & \\
\hline & Total & 34 & 12 & 2 & 3 \\
\hline
\end{tabular}

\begin{tabular}{|c|c|c|c|c|c|c|}
\hline \multirow[t]{8}{*}{2} & $\begin{array}{l}\text { Tenaga } \\
\text { keperawatan }\end{array}$ & & & & & \\
\hline & Perawat ahli & 28 & 24 & & 6 & \\
\hline & $\begin{array}{l}\text { Perawat } \\
\text { terampil }\end{array}$ & 104 & 57 & & 21 & \\
\hline & $\begin{array}{l}\text { D.III perawat } \\
\text { gigi }\end{array}$ & 1 & & & & \\
\hline & SPRG & 1 & & & & \\
\hline & D. IV Anastesi & 1 & & & & \\
\hline & D.III Anastesi & 1 & & & & \\
\hline & Total & 116 & 81 & & 27 & - \\
\hline \multirow[t]{5}{*}{3} & $\begin{array}{l}\text { Tenaga } \\
\text { kebidanan }\end{array}$ & & & & & \\
\hline & $\begin{array}{l}\text { D.IV } \\
\text { Kebidanan/S1 }\end{array}$ & 5 & & & & \\
\hline & $\begin{array}{ll}\text { D.III } & 16 \\
\text { Kebidanan } & \end{array}$ & 27 & & 41 & & \\
\hline & $\begin{array}{ll}\text { D.I } & 1 \\
\text { Kebidanan } & \\
\end{array}$ & & & & & \\
\hline & Total & 27 & & $\underline{41}$ & - & \\
\hline
\end{tabular}

Tabel 1 menunjukan alasan peneliti mengambil tempat penelitian di RSUD Dr. M.M Dunda Limboto yaitu jumlah populasi yang banyak sehingga tercukupi jumlah sampel, selain itu tempat RSUD Dr. M.M Dunda sangat strategis sehingga dijadikan rumah sakit rujukan daerah yang ada di Kabupaten Gorontalo, sebagai rumah sakit rujukan daerah RSUD Dr. M.M banyak melayani pasien patologi seperti KPD dan lain-lain.

Tabel 2

\begin{tabular}{ccc}
$\begin{array}{c}\text { Distribusi Frekuensi Karakteristik } \\
\text { Responden }\end{array}$ \\
\hline Umur & Jumlah & Presentase \% \\
\hline$<20$ tahun & 8 & 21 \\
\hline $20-30$ tahun & 26 & 68.5 \\
\hline$>30$ tahun & 4 & 10.5 \\
\hline Pendidikan & & \\
\hline SD & 14 & 36.8 \\
\hline SMP & 7 & 18.4 \\
\hline SMA & 14 & 36.8 \\
\hline Sarjana & 3 & 7.9 \\
\hline Paritas & & \\
\hline Primipara & 15 & 39.5 \\
\hline multipara & 23 & 60.5 \\
\hline Total & $\mathbf{3 8}$ & $\mathbf{1 0 0}$ \\
\hline & &
\end{tabular}

Berdasarkan tabel 2. menunjukan bahwa frekuensi umur responden tertinggi yaitu pada responden dengan umur 20-30 tahun dengan jumlah 26 orang atau presentase $68.5 \%$ dan frekuensi umur responden 
terendah yaitu responden dengan umur $>30$ tahun dengan jumlah 4 orang atau presentase $10.5 \%$. Sedangkan frekuensi Pendidikan responden tertinggi yaitu responden dengan pendidikan SD dan SMA masing-masing berjumlah 14 orang dengan presentase $36.8 \%$ dan yang terendah yaitu responden dengan pendidikan sarjana dengan jumlah 3 orang presentase $7.9 \%$. Pada frekuensi Paritas tertinggi yaitu responden dengan paritas multipara berjumlah 23 orang dengan presentasi 60.5 dan terendah responden dengan paritas primipara dengan jumlah 15 orang atau presentasi $39.5 \%$.

\section{Analisis Univariat}

Tabel 3

Distribusi Frekuensi Analisis Univariat

\begin{tabular}{ccc}
\hline Pekerjaan & Jumlah & $\begin{array}{c}\text { Presentase } \\
\text { \% }\end{array}$ \\
\hline Bekerja & 14 & 36.8 \\
\hline Tidak bekerja & 24 & 63.2 \\
\hline $\begin{array}{c}\text { Kelainan letak } \\
\text { janin }\end{array}$ & & \\
\hline Sunsang & 19 & 50.0 \\
\hline Lintang & 19 & 50.0 \\
\hline BB janin & & \\
\hline BBLR <2500 & 8 & 21.1 \\
\hline $\begin{array}{c}\text { Normal 2500- } \\
\text { 4000 }\end{array}$ & 27 & 71.1 \\
\hline $\begin{array}{c}\text { Makrosemia } \\
\text { >4000 }\end{array}$ & 3 & 7.9 \\
\hline Gemeli & & \\
\hline Gemeli & 12 & 31.6 \\
\hline Tidak gemeli & 26 & 68.4 \\
\hline Kejadian KPD & & \\
\hline KPD & 19 & 50.0 \\
\hline Tidak KPD & 19 & 50.0 \\
\hline Total & $\mathbf{3 8}$ & $\mathbf{1 0 0}$ \\
\hline & & \\
\hline
\end{tabular}

Berdasarkan tabel 3 menunjukan bahwa frekuensi responden yang bekerja berjumlah 14 orang dengan presentase $36.8 \%$ dan responden yang tidak bekerja berjumlah 24 dengan presentase $63.2 \%$. Pada kelainan letak janin menunjukan bahwa frekuensi responden dengan kehamilan sunsang dan lintang berjumlah masing-masing 19 orang dengan presentase $50.0 \%$. Sedangkan pada BB janin menunjukan bahwa frekuensi responden tertinggi yaitu responden dengan BB janin normal berjumlah 27 orang atau presentase $71.1 \%$ dan yang terendah yaitu responden dengan $\mathrm{BB}$ janin $>4000$ (makrosemia) berjumlah 3 orang atau presentase $7.9 \%$. Serta pada kejadian gemeli menunjukan bahwa frekuensi responden tertinggi yaitu responden yang tidak gemeli berjumlah 26 orang atau presentase $68.4 \%$ dan yang terendah yaitu responden yang gemeli berjumlah 12 orang atau presentase $31.6 \%$. pada kejadian KPD menunjukan bahwa frekuensi responden yang mengalami KPD sebanyak 19 orang dengan presentase $50.0 \%$ dan yang tidak KPD sebanyak 19 orang dengan presentase $50.0 \%$

2. Analisis Bivariat

Tabel 4

Distribusi Frekuensi Hubungan Pekerjaan Dengan Kejadian KPD

\begin{tabular}{|c|c|c|c|c|c|}
\hline \multicolumn{6}{|c|}{ Pekerjaan } \\
\hline $\begin{array}{c}\text { Kejadian } \\
\text { KPD }\end{array}$ & $\begin{array}{l}\text { Bek } \\
\text { erja }\end{array}$ & $\begin{array}{c}\text { Tida } \\
\text { k } \\
\text { Beke } \\
\text { rja }\end{array}$ & $\begin{array}{c}\text { T } \\
\text { ot } \\
\text { al }\end{array}$ & $\begin{array}{c}\text { OR } \\
95 \\
\% \\
\text { CI } \\
\end{array}$ & $\begin{array}{c}P=V a \\
\text { lue }\end{array}$ \\
\hline KPD & 4 & 15 & 19 & & \\
\hline Tidak KPD & 10 & 9 & 19 & $\begin{array}{c}4.16 \\
7\end{array}$ & 0.044 \\
\hline Total & 14 & 24 & 38 & & \\
\hline
\end{tabular}

Tabel 4 menunjukkan bahwa responden mengalami KPD yang bekerja sebanyak 4 orang dan yang tidak bekerja sebanyak 15 orang. Sedangkan responden tidak mengalami KPD yang bekerja sebanyak 10 dan yang tidak bekerja sebanyak 9 orang. Diketahui nilai chi square hitung >chi square tabel (4.071> 3.841) atau $\mathrm{p}=0.044<0.05$, maka $\mathrm{H} 0$ ditolak, jadi dapat simpulkan bahwa ada hubungan pekerjaan responden dengan Ketuban Pecah Dini (KPD) dan OR: 4.167 artinya ibu yang bekerja selama kehamilan memiliki 4 kali beresiko untuk mengalami ketuban pecah dini. 
Tabel 5

\begin{tabular}{|c|c|c|c|c|c|}
\hline \multicolumn{6}{|c|}{$\begin{array}{l}\text { Distribusi Frekuensi Hubungan Kelainan } \\
\text { Letak Janin Dengan Keiadian KPD }\end{array}$} \\
\hline \multicolumn{6}{|c|}{ Kelainan Letak Janin } \\
\hline $\begin{array}{l}\text { Kejadi } \\
\text { an } \\
\text { KPD }\end{array}$ & $\begin{array}{l}\text { Sunsa } \\
\text { ng }\end{array}$ & $\begin{array}{l}\text { Lint } \\
\text { ang }\end{array}$ & $\begin{array}{l}\text { Tot } \\
\text { al }\end{array}$ & $\begin{array}{l}\text { OR } \\
95 \% \mathrm{CI}\end{array}$ & $\begin{array}{l}\mathrm{P}=\mathrm{Va} \\
\text { lue }\end{array}$ \\
\hline KPD & $\underline{9}$ & 10 & $\underline{19}$ & \multirow{3}{*}{.810} & \multirow{3}{*}{0.746} \\
\hline $\begin{array}{l}\text { Tidak } \\
\text { KPD }\end{array}$ & 10 & 9 & 19 & & \\
\hline Total & 19 & 19 & $\underline{38}$ & & \\
\hline
\end{tabular}

Tabel 5 menunjukkan bahwa respoden yang mengalami KPD dengan posisi janin sunsang sebanyak 9 orang dan posisi janin lintang sebanyak 10 orang. Sedangkan responden yang tidak mengalami KPD dengan posisi janin sunsang sebanyak 10 orang dan lintang sebanyak 9 orang. Diketahui nilai chi square hitung < chi square tabel $(0.105$ <3.841) atau $\mathrm{p}=0.746>0.05$, maka $\mathrm{H} 0$ diterima, jadi dapat simpulkan bahwa tidak ada hubungan kelainan letak janin dengan Ketuban Pecah Dini (KPD) dan OR: 0.810 artinya ibu dengan kelainan letak janin tidak beresiko untuk mengalami ketuban pecah dini.

Tabel 6

Distribusi Frekuensi Hubungan BB Janin Dengan Kejadian KPD

\begin{tabular}{|c|c|c|c|c|c|c|}
\hline \multicolumn{7}{|c|}{ BB Janin } \\
\hline $\begin{array}{c}\text { Kejadian } \\
\text { KPD }\end{array}$ & $\begin{array}{c}\text { BBL } \\
\text { R } \\
<\mathbf{2 5 0} \\
0\end{array}$ & $\begin{array}{c}\text { Nor } \\
\text { mal } \\
2500 \\
- \\
4000\end{array}$ & $\begin{array}{c}\text { Makr } \\
\text { osemi } \\
\mathbf{a} \\
>4000\end{array}$ & $\begin{array}{c}\text { Tota } \\
1\end{array}$ & $\begin{array}{l}\text { OR } \\
95 \% \\
\text { CI }\end{array}$ & $\begin{array}{l}\mathbf{P}= \\
\text { Va } \\
\text { lue }\end{array}$ \\
\hline KPD & 3 & 15 & 1 & 19 & & \\
\hline $\begin{array}{l}\text { Tidak } \\
\text { KPD }\end{array}$ & 5 & 12 & 2 & 19 & $\begin{array}{c}0.82 \\
4\end{array}$ & $\begin{array}{l}0.5 \\
55\end{array}$ \\
\hline Total & 8 & 27 & 3 & 38 & & \\
\hline
\end{tabular}

Tabel 6 Diperoleh hasil bahwa responden yang mengalami KPD dengan BB janin <2500 atau BBLR sebanyak 3 orang dan responden dengan $\mathrm{BB}$ janin normal 2500-4000 sebanyak 15 orang serta responden dengan $\mathrm{BB}$ janin $>4000$ atau makrosemia sebanyak 1 orang. Sedangkan responden yang tidak mengalami KPD tidak dengan BB janin $<2500$ atau BBLR sebanyak 5 orang dan responden dengan BB janin normal 25004000 sebanyak 12 orang serta BB janin $>4000$ atau makrosemia sebanyak 2 orang. Diketahui nilai chi square hitung < chi square tabel $(1.179>3.841)$ atau $\mathrm{p}=0.555>0.05$, maka H0 diterima, jadi dapat simpulkan bahwa tidak ada hubungan BB janin dengan Ketuban Pecah Dini (KPD) dan OR: 0.824 artinya ibu dengan BB janin tidak beresiko untuk mengalami ketuban pecah dini.

\section{Tabel 7}

Distribusi Frekuensi Hubungan Gemeli Dengan Kejadian KPD

\begin{tabular}{|c|c|c|c|c|c|}
\hline \multicolumn{6}{|c|}{ Gemeli } \\
\hline $\begin{array}{c}\text { Kejadi } \\
\text { an } \\
\text { KPD }\end{array}$ & $\begin{array}{c}\mathbf{K P} \\
\mathbf{D}\end{array}$ & $\begin{array}{c}\text { Tida } \\
\mathbf{k} \\
\text { KPD }\end{array}$ & $\begin{array}{l}\text { To } \\
\text { tal }\end{array}$ & $\begin{array}{c}\text { OR } \\
95 \% \\
\text { CI } \\
\end{array}$ & $\begin{array}{c}P=\text { Val } \\
\text { ue }\end{array}$ \\
\hline KPD & 3 & 15 & 1 & & \\
\hline $\begin{array}{l}\text { Tidak } \\
\text { KPD }\end{array}$ & 5 & 12 & 2 & $\begin{array}{c}1.00 \\
0\end{array}$ & 0.721 \\
\hline Total & 8 & $\underline{27}$ & 3 & & \\
\hline
\end{tabular}

Sumber: Data primer (2020)

Tabel 7 Diperoleh hasil bahwa responden yang mengalami KPD dengan kejadian gemeli sebanyak 3 orang dan tidak KPD sebanyak 15 orang. Sedangkan responden yang tidak KPD mengalami kejadian gemeli sebanyak 5 orang dan tidak KPD sebanyak 19 orang. Diketahui nilai chi square hitung < chi square tabel $(0.128<3.841)$ atau $\mathrm{p}=0.721>0.05$, maka H0 diterima, jadi dapat simpulkan bahwa tidak ada hubungan gemeli dengan Ketuban Pecah Dini (KPD) dan OR: 1.000 artinya ibu dengan gemeli tidak beresiko untuk mengalami ketuban pecah dini.

Berdasarkan hasil peneltian yang telah dilakukan oleh peneliti dan peneliti sebelumnya dapat disimpulkan bahwa gemeli merupakan faktor terjadinya ketuban pecah dini namun ditemukan tidak 
semua pasien dengan gemeli mengalami ketuban pecah dini karena terdapat banyak faktor terjadinya ketuban pecah dini sehigga deteksi dini untuk pencegahan hal ini yaitu melakukan pemeriksaan secara rutin agar bidan dapat mendeteksi secara dini mengenai komplikasi yang akan ibu alami.

Tabel 1 menunjukkan bahwa Pada adalah hasil analisi univariat yang menunjukan bahwa frekuensi responden bekerja berjumlah 14 orang dengan presentase $36.8 \%$ dan responden yang tidak bekerja berjumlah 24 dengan presentase $63.2 \%$. Hasil analisis bivariat menunjukan bahwa responden mengalami KPD yang bekerja sebanyak 4 orang dan yang tidak bekerja sebanyak 15 orang. Sedangkan responden tidak mengalami KPD yang bekerja sebanyak 10 dan yang tidak bekerja sebanyak 9 orang. Diketahui nilai chi square hitung $>$ chi square tabel $(4.071>3.841)$ atau $\mathrm{p}=0.044<0.05$, maka H0 ditolak, jadi dapat simpulkan bahwa ada hubungan pekerjaan responden dengan Ketuban Pecah Dini (KPD) dan OR: 4.167 artinya ibu yang bekerja selama kehamilan memiliki 4 kali beresiko untuk mengalami ketuban pecah dini.

Penelitian ini sejalan dengan penelitian yang dilakukan (Tahir, 2014) menunjukkan hasil penelitian bahwa sebagian besar ibu yang mengalami KPD bekerja sebagai ibu rumah tangga dibandingkan wiraswasta. Pekerjaan sebagai ibu rumah tangga dapat menguras energi, karena seorang ibu hamil harus bekerja sepanjang hari tanpa pamrih mengurus rumah tangga demi kebahagiaan keluarganya.

Berdasarkan penelitian yang dilakukan oleh (Leihitu, 2015). Kejadian ketuban pecah dini preterm dengan status pekerjaan ibu bekerja sebanyak $12(17 \%)$ orang dan yang status pekerjaannya ibu tidak bekerja sebanyak 59 (83\%) orang sehingga totalnya 71 orang. Sedangkan kejadian ketuban pecah dini aterm dengan status pekerjaan ibu bekerja sebanyak 14 (12\%) orang dan yang status pekerjaannya ibu tidak bekerja sebanyak 105 (88\%) orang sehingga totalnya 119 orang (Leihitu, 2015).

Berdasarkan penelitian yang dilakukan oleh (Rohmawati \& Wijayanti, 2018). Pada Uji Chi Square penelitian ini di dapatkan beberapa faktor yang memiliki pengaruh secara signifikan terhadap ketuban pecah dini, yaitu infeksi $(0,000)$, anemia $(0,007)$, senam hamil $(0,000)$, posisi janin $(0,009)$, dan riwayat KPD $(0,002)$ yang memiliki nilai $\mathrm{p}$ value $<0,05$. Sedangkan faktor umur $(0,132)$, paritas $(0,678)$, pekerjaan $(1,000)$, trauma $(0,385)$ dan gemeli $(0,250)$ tidak memiliki pengaruh secara signifikan terhadap ketuban pecah dini. Kemudian pada Uji Odds Ratio didapatkan hasil faktor umur $(2,320)$, infeksi $(22,857)$, anemia $(6,047)$, trauma $(1,680)$, gemeli $(4,188)$, posisi janin $(10,208)$ dan riwayat KPD $(11,200)$ memiliki nilai OR > 1 sehingga faktor tersebut menyebabkan terjadinya ketuban pecah dini. Sedangkan faktor paritas $(0,892)$, pekerjaan $(0,733)$ dan senam hamil $(0,031)$ memiliki nilai $\mathrm{OR}<1$ yang artinya faktor tersebut mencegah terjadinya Ketuban Pecah Dini (Rohmawati \& Wijayanti, 2018).

Penelitian yang dilakukan oleh (Rosmiarti, 2016) Pola pekerjaan ibu hamil berpengaruh terhadap kebutuhan energi. Kerja fisik pada saat hamil yang terlalu berat dan dengan lama kerja melebihi 3 jam perhari dapat berakibat kelelahan (Rosmiarti, 2016). Kelelahan dalam bekerja akan menyebabkan korion amnion melemah sehingga dapat terjadi ketuban pecah dini. Lalu (Tahir, 2014) menunjukkan hasil penelitian bahwa sebagian besar ibu yang mengalami KPD bekerja sebagai ibu rumah tangga 
dibandingkan wiraswasta. Pekerjaan sebagai ibu rumah tangga dapat menguras energi, karena seorang ibu hamil harus bekerja sepanjang hari tanpa pamrih mengurus rumah tangga demi kebahagiaan keluarganya (Tahir, 2014).

Menurut (Rosmiarti, 2016) pola pekerjaan ibu hamil berpengaruh terhadap kebutuhan energi. Kerja fisik pada saat hamil yang terlalu berat dan dengan lama kerja melebihi 3 jam perhari dapat berakibat kelelahan. Kelelahan dalam bekerja akan menyebabkan korion amnion melemah sehingga dapat terjadi ketuban pecah dini.11 Lalu (Tahir, 2014) menunjukkan hasil penelitian bahwa sebagian besar ibu yang mengalami KPD bekerja sebagai ibu rumah tangga dibandingkan wiraswasta. Pekerjaan sebagai ibu rumah tangga dapat menguras energi, karena seorang ibu hamil harus bekerja sepanjang hari tanpa pamrih mengurus rumah tangga demi kebahagiaan keluarganya (Tahir, 2014). Hasil dari penelitian yang tidak berhubungan bisa terjadi karena factor sosio-ekonomi, salah satunya pola pekerjaan. Pola pekerjaan ibu hamil berpengaruh terhadap kebutuhan energi. Pekerjaan fisik yang terlalu berat dan lama kerja > 3 jam pada saat hamil dapat mengakibatkan kelelahan. Pekerjaan merupakan suatu yang penting dalam kehidupan, namun pada masa kehamilan pekerjaan yang berat dan dapat membahayakan kehamilannya hendaklah dihindari untuk menjaga keselamatan ibu maupun janin (Notoatmdojo, 2014).

Berdasarkan hasil penelitian yang didapatkan dan penelitian yang dilakukan oleh peneliti sebelumnya dapat disimpulkan bahwa status pekerjaan ibu hamil dapat menyebabkan terjadinya ketuban pecah dini hal ini karena aktifitas saat bekerja memerlukan energi yang banyak sehingga keadaa fisik ibu hamil menjadi lelah, ibu hamil yang mengalami kelelahan dalam bekerja menyebabkan lemahnya korion amnion sehingga timbul ketuban pecah dini, terdapat banyak faktor terjadinya ketuban pecah dini sehigga deteksi dini untuk pencegahan hal ini yaitu melakukan pemeriksaan secara rutin agar bidan dapat mendeteksi secara dini mengenai komplikasi yang akan ibu alami.

Peneliti berasumsi bahwa dalam penelitian ini menunjukan bahwa pekerjaan bisa mempengaruhi terjadinya KPD, dari hasil diatas terdapat 14 orang ibu hamil yang tidak bekerja mengalami KPD, ibu hamil yang tidak bekerja bukan berarti tidak memiliki kegiatan, ibu hamil yang pekerjaannya sebagai ibu rumah tangga memiliki lebih banyak kesibukan dibandingkan ibu hamil yang bekerja dikantoran hal ini karena pekerjaan rumah yang tidak pernah selesai dan merupakan pekerjaan yang selalu berulang seperti (memasak, mencuci, menyapu dll).

Tabel 2 Pada hasil analisi univariat menunjukan bahwa frekuensi responden dengan kehamilan sungsang dan lintang berjumlah sama yaitu masing-masing 19 orang dengan presentase $50.0 \%$. Hasil analisis bivariat bahwa respoden yang mengalami KPD dengan posisi janin sungsang sebanyak 9 orang dan posisi janin lintang sebanyak 10 orang. Sedangkan responden yang tidak mengalami KPD dengan posisi janin sungsang sebanyak 10 orang dan lintang sebanyak 9 orang. Diketahui nilai chi square hitung < chi square tabel $(0.105<$ 3.841) atau $\mathrm{p}=0.746>0.05$, maka $\mathrm{H} 0$ diterima, jadi dapat simpulkan bahwa tidak ada hubungan kelainan letak janin dengan Ketuban Pecah Dini (KPD) dan OR: 0.810 artinya ibu dengan kelainan letak janin tidak beresiko untuk mengalami ketuban pecah dini.

Menurut (Isnaini, 2015) Insiden ketuban pecah dini lebih tinggi pada wanita dengan kelainan letak. Salah satu 
contoh kelainan letak yaitu presentasi bokong atau letak sungsang dimana keadaan tersebut dapat berlangsung lama karena yang menekan jalan lahir bukan kepala melainkan bokong sehingga berakibat pembukaan menjadi lama dan mudah untuk menjadi ketuban pecah dini. Kehamilan presentasi bokong bila dibandingkan dengan kehamilan presentasi kepala akan menghadapi risiko yang lebih besar baik pada ibu maupun bayi. Semua persalinan mengalami insiden dari presentasi bokong sebesar 3\%. Sebab terjadinya letak sungsang adalah multipara, prematuritas, hidramnion, plasentas previa, kelainan bentuk kepala (anensefalus, dan hidrosefalus), kehamilan ganda, panggul sempit dan tumor pelvis (Isnaini, 2015).

Penelitian ini tidak sejalan dengan penelitian yang dilakukan (Luwarsih \& Ruhyana, 2014) uji statistik Chi Square dengan $\mathrm{p}$ value $=0,05$ didapatkan hasil Asymp.Sig pada variabel letak janin dengan nilai $\mathrm{p}=0,001$, pada variabel gemili dengan nilai Asymp.Sig $\mathrm{p}=0,005$, pada variabel status pekerjaan nilai Asymp.Sig $\mathrm{p}=0,009$ yang berarti ada hubungan antara letak janin, gemeli dan status pekerjaan dengan ketuban pecah dini. Sedangkan hasil uji Kendall Tau dengan $\mathrm{p}$ value $=0,05$ pada variabel usia ibu didapatkan hasil Asymp.Sig dengan nilai $\mathrm{p}=0,000$ yang berarti ada hubungan antara usia ibu dengan ketuban pecah dini (Luwarsih \& Ruhyana, 2014).

Faktor yang berhubungan dengan kejadian Ketuban pecah dini yaitu Infeksi, kehamilan kembar, hidramnion, serviks inkompeten, letak janin, fisiologis selaput ketuban abnormal, usia, paritas, perdarahan anterpartum, riwayat abortus, riwayat persalinan preterm, riwayat ketuban pecah dini sebelumnya, ukuran panggul, ketegangan rahim yang berlebihan, status pekerjaan, hubungan seksual, pemeriksaan dalam dan amniosintesis (Luwarsih \& Ruhyana, 2014).

Kelainan yang paling sering terjadi dikarenakan kelemahan otot-otot uterus dan abdomen. Sering juga tidak diteukan faktor etiooisnya dan dianggap kebetulan. Karena bagian terendah tidak menutup PAP, ketuban cenderung pecah dini dan dapat disertai menumbungnya tangan janin atau tali pusar Kemudian (Huda et al., 2013) menjelaskan hasil bahwa sungsang berpengaruh secara signifikan terhadap ketuban pecah dini, karena bokong dengan kedua tungkai yang terlipat lebih besar dari pada kepala yang memungkinkan ketegangan rahim meningkat, sehingga membuat selaput ketuban pecah sebelum waktunya.

Berdasarkan hasil peneltian yang telah dilakukan oleh peneliti dan peneliti sebelumnya dapat disimpulkan bahwa kelainan letak janin berpengaruh terhadap terjadinya kejadian ketuban pecah dini namun dalam penelitian tidak ditemukan adanya pengaruh letak janin dengan ketuban pecah dini, ketuban pecah dini terjadi akibat beberapa faktor yiatu seperti pengetahuan, pendidikan, pekerjaan ibu, infeksi, kelainan letak janin, BB janin, ukuran panggul dan riwayat KPD, terdapat banyak faktor terjadinya ketuban pecah dini sehigga deteksi dini untuk pencegahan hal ini yaitu melakukan pemeriksaan secara rutin agar bidan dapat mendeteksi secara dini mengenai komplikasi yang akan ibu alami.

Peneliti berasumsi bahwa posisi janin sungsang lebih beresiko terjadinya ketuban pecah dini dibandingkan dengan posisi janin lintang yaitu posisi sungsang 9 orang responden yang mengalami KPD dan 10 orang responden dengan posisi janin lintang, sedangkan responden yang tidak mengalami KPD dengan posisi janin sungsang sebanyak 10 orang dan lintang 
sebanyak 9 orang. Namun dalam penelitian ini ditemukan bahwa posisi janin tidak mempengaruhi terjadinya ketuban pecah dini hal ini dikarenakan posisi janin sungsang atau lintang tidak terdapat tekanan pada ketuban sehingga ketuban tetap utuh, terjadinya ketuban pecah dini dapat dipengaruhi oleh beberapa faktor sehingga kelainan letak janin tidak selalu berhubungan dengan ketuban pecah dini.

Tabel 3 menunjukkan Pada hasil analisi univariat menunjukan bahwa frekuensi responden tertinggi yaitu responden dengan BB janin normal berjumlah 27 orang presentase $71.1 \%$ dan yang terendah yaitu responden dengan BB janin >4000 (makrosemia) berjumlah 3 orang presentase $7.9 \%$. Hasil analisis bivariat menunjukan bahwa hasil bahwa responden yang mengalami KPD dengan BB janin <2500 atau BBLR sebanyak 3 orang dan responden dengan $\mathrm{BB}$ janin normal 2500-4000 sebanyak 15 orang serta responden dengan $\mathrm{BB}$ janin $>4000$ atau makrosemia sebanyak 1 orang. Sedangkan responden yang tidak mengalami KPD tidak dengan BB janin $<2500$ atau BBLR sebanyak 5 orang dan responden dengan BB janin normal 25004000 sebanyak 12 orang serta BB janin $>4000$ atau makrosemia sebanyak 2 orang. Diketahui nilai chi square hitung < chi square tabel $(1.179>3.841)$ atau $\mathrm{p}=0.555$ $>0.05$, maka H0 diterima, jadi dapat simpulkan bahwa tidak ada hubungan BB janin dengan Ketuban Pecah Dini (KPD) dan OR: 0.824 artinya ibu dengan BB janin tidak beresiko untuk mengalami ketuban pecah dini.

Sejalan dengan hasil penelitian (Nugroho, 2010). Menyatakan bahwa ketuban pecah dini berpengaruh terhadap kejadian BBLR pada persalinan usia kehamilan 34-36 minggu dengan nilai $\mathrm{p}<$ 0,0001 .
Teori (Manuaba, 2010), mendukung yakni ketuban pecah dini juga menyebabkan oligohidramnion yang mana hal ini dapat menekan tali pusat sehingga janin mengalami asfiksia dan hipoksia yang menyebabkan aliran oksigen dan nutrisi ke janin tidak maksimal sehingga menganggu pertumbuhannya. Ketuban pecah dini merupakan komplikasi dari kehamilan. Bila usia kehamilan belum cukup bulan, namun selaput ketuban telah pecah maka akan mempengaruhi berat badan bayi yang dilahirkan yang mengakibatkan kelahiran premature dan beresiko melahirkan bayi dengan prematuritas murni yang termasuk dalam kategori BBLR.

Berat bayi yang sangat kecil atau sangat besar berhubungan dengan meningkatnya komplikasi selama masa persalinan dan nifas. Hal yang paling sering terjadi pada janin dengan berat lahir besar (makrosomia) salah satunya adalah distosia bahu. Sedangkan pada ibu dapat terjadi perlukaan jalan lahir, trauma pada otot-otot dasar panggul dan perdarahan pasca persalinan. Pada bayi dengan berat lahir rendah dapat terjadi respiratory distress syndrom atau hipoglikemi (Winkjosastro, 2012).

Berdasarkan hasil peneltian yang telah dilakukan oleh peneliti dan peneliti sebelumnya dapat disimpulkan bahwa BB janin dapat menyebabkan terjadinya ketuban pecah dini namun dalam penelitian ini tidak ditemukan pengaruh BB janin terhadap terjadinya ketuban pecah dini hal ini karena ketuban pecah dini terjadi akibat beberapa faktor yiatu seperti pengetahuan, pendidikan, pekerjaan ibu, infeksi, kelainan letak janin, BB janin, ukuran panggul dan riwayat KPD, terdapat banyak faktor terjadinya ketuban pecah dini sehigga deteksi dini untuk pencegahan hal ini yaitu melakukan pemeriksaan secara rutin agar bidan dapat 
mendeteksi secara dini mengenai komplikasi yang akan ibu alami.

Peneliti berasumsi bahwa BB janin 2500-4000 sangat rentang terjadinya ketuban pecah dini, hal ini karena tekanan kepala bayi dengan BB normal terhadap ketuban sangat mungkin terjadi, dalam penelitian ini terdapat bayi dengan BB kurang yang mengalami ketuban pecah dini hal ini disebabkan oleh faktor lain yang menyebabkan terjadinya ketuban pecah dini faktor lain yang dimaksud seperti, infeksi, riwayat KPD, gemeli, makrosemia, status pekerjaan ibu, paritas.

Tabel 4 menunjukkan Pada hasil analisi univariat menunjukan bahwa frekuensi responden tertinggi yaitu responden yang tidak gemeli berjumlah 26 orang presentase $68.4 \%$ dan yang terendah yaitu responden yang gemeli berjumlah 12 orang presentase $31.6 \%$. Hasil analisis bivariat menunjukan hasil bahwa responden yang mengalami KPD dengan kejadian gemeli sebanyak 3 orang dan tidak KPD sebanyak 15 orang. Sedangkan responden yang tidak KPD mengalami kejadian gemeli sebanyak 5 orang dan tidak KPD sebanyak 19 orang. Diketahui nilai chi square hitung < chi square tabel $(0.128<3.841)$ atau $\mathrm{p}=0.721>0.05$, maka H0 diterima, jadi dapat simpulkan bahwa tidak ada hubungan gemeli dengan Ketuban Pecah Dini (KPD) dan OR: 1.000 artinya ibu dengan gemeli tidak beresiko untuk mengalami ketuban pecah dini.

Hasil penelitian ini tidak sejalan dengan hasil penelitian yang dilakukan oleh (Meliati, 2018) menunjukkan hasil bahwa Ibu yang kejadian persalinan gemelli mempunyai peluang resiko lebih tinggi dibandingkan kehamilan gemeli terhadap kejadian ketuban pecah dini, maka persalinan pada kehamilan kembar besar kemungkinan terjadi masalah seperti ketuban pecah dini, resusitasi neonatus, prematuritas, perdarahan postpartum, malpresentasi kembar kedua, atau perlunya seksio sesaria.

Berdasarkan penelitian yang dilakukan oleh (Tahir, 2014) di RSUD Syekh Yusuf Kabupaten Gowa ibu dengan kehamilan ganda yang mengalami KPD sebesar $11,0 \%$, dari analisa data ibu yang mengalami kehamilan ganda beresiko 3 kali lebih besar dibanding dengan ibu yang tidak dengan kehamilan ganda.

Penelitian ini sejalan dengan penelitian yang dilakukan oleh (Rohmawati \& Wijayanti, 2018). Pada Uji Chi Square penelitian ini di dapatkan beberapa faktor yang memiliki pengaruh secara signifikan terhadap ketuban pecah dini, yaitu infeksi $(0,000)$, anemia $(0,007)$, senam hamil $(0,000)$, posisi janin $(0,009)$, dan riwayat KPD $(0,002)$ yang memiliki nilai $\mathrm{p}$ value $<0,05$. Sedangkan faktor umur $(0,132)$, paritas $(0,678)$, pekerjaan $(1,000)$, trauma $(0,385)$ dan gemeli $(0,250)$ tidak memeliki pengaruh secara signifikan terhadap ketuban pecah dini. Kemudian pada Uji Odds Ratio didapatkan hasil faktor umur (2,320), infeksi (22,857), anemia $(6,047)$, trauma $(1,680)$, gemeli $(4,188)$, posisi janin $(10,208)$ dan riwayat KPD $(11,200)$ memiliki nilai OR > 1 sehingga faktor tersebut menyebabkan terjadinya ketuban pecah dini. Sedangkan faktor paritas $(0,892)$, pekerjaan $(0,733)$ dan senam hamil $(0,031)$ memiliki nilai.

Menurut (Ridwan \& Herlina, 2017) mengatakan bawa kehamilan ganda merupakan kehamilan dengan ukuran uterus yang lebih besar dibanding umur kehamilannya, sehingga terjadi keregangan rahim berlebihan. Hal tersebut akan meningkatkan tekanan intrauterin, dengan tekanan yang berlebihan ini vaskularisasi tidak berjalan dengan lancar yang dapat mengakibatkan selaput ketuban kekurangan jaringan ikat. Sehingga menyebabkan selaput ketuban tidak kuat atau lemah dan bila terjadi sedikit 
pembukaan servik saja maka selaput ketuban akan mudah pecah. Dan juga termasuk ke dalam faktor predisposisi ketuban pecah dini yaitu tekanan intra uterin yang meninggi atau meningkat secara berlebihan (overdistensi uterus) salah satunya dikarenakan kehamilan ganda/gamelli.

Adapun beberapa faktor yang mempengaruhi kejadian ketuban pecah dini yaitu Faktor kehamilan kembar juga berpengaruh, karena janin lebih dari satu sehingga rongga rahim menjadi lebih sempit dan mengakibatkan kontraksi menjadi lebih kuat. Berdasarkan penelitian yang dilakukan oleh (Tahir, 2014) Sebanyak (89\%) pada ibu yang tidak mengalami kehamilan kembar lebih besar mengalami kejadian ketuban pecah dini dibanding ibu yang tidak hamil kembar.

Berdasarkan hasil peneltian yang telah dilakukan oleh peneliti dan peneliti sebelumnya dapat disimpulkan bahwa gemeli merupakan faktor terjadinya ketuban pecah dini namun ditemukan tidak semua pasien dengan gemeli mengalami ketuban pecah dini karena terdapat banyak faktor terjadinya ketuban pecah dini sehigga deteksi dini untuk pencegahan hal ini yaitu melakukan pemeriksaan secara rutin agar bidan dapat mendeteksi secara dini mengenai komplikasi yang akan ibu alami.

Menurut (Prawirohardjo, S. \& Wiknjosastro, 2014) yang harus dilakukan saat terjadi ketuban pecah dini yaitu memastika diagnosa terlebih dahulu, kemudian menentukan umur kehamilan, mengevaluasi ada tidaknya infeksi maternal ataupun infeksi janin dan memastikan apakah dalam keadaan inpartu terdapat gawat janin atau tidak.

Peneliti berasumsi bahwa ibu dengan gemeli beresiko mengalami ketuban pecah dini berdasarkan hasil penelitian bahwa ibu dengan gemeli mengalami ketuban pecah dini sebanyak 3 orang dan yang tidak mengalami ketuban pecah dini dengan kehamilan gemeli sebanyak 5 orang, ketuban pecah dini terjadi akibat beberapa faktor salah satunya kehamilan dengan gemeli.

\section{Kesimpulan}

Diketahui nilai chi square hitung >chi square tabel $(4.071>3.841)$ atau $\mathrm{p}=0.044<0.05$, maka H0 ditolak, jadi dapat simpulkan bahwa ada hubungan pekerjaan responden dengan Ketuban Pecah Dini (KPD) dan OR: 4.167 artinya ibu yang bekerja selama kehamilan memiliki 4 kali beresiko untuk mengalami ketuban pecah dini. Diketahui nilai chi square hitung < chi square tabel $(0.105<3.841)$ atau $\mathrm{p}=0.746>0.05$, maka H0 diterima, jadi dapat simpulkan bahwa tidak ada hubungan kelainan letak janin dengan Ketuban Pecah Dini (KPD) dan OR: 0.810 artinya ibu dengan kelainan letak janin tidak beresiko untuk mengalami ketuban pecah dini. Diketahui nilai chi square hitung < chi square tabel (1.179 > 3.841) atau $\mathrm{p}=0.555>0.05$, maka H0 diterima, jadi dapat simpulkan bahwa tidak ada hubungan BB janin dengan Ketuban Pecah Dini (KPD) dan OR: 0.824 artinya ibu dengan BB janin tidak beresiko untuk mengalami ketuban pecah dini. Diketahui nilai chi square hitung < chi square tabel $(0.128<3.841)$ atau $\mathrm{p}=0.721>0.05$, maka H0 diterima, jadi dapat simpulkan bahwa tidak ada hubungan gemeli dengan Ketuban Pecah Dini (KPD) dan OR: 1.000 artinya ibu dengan gemeli tidak beresiko untuk mengalami ketuban pecah dini.

\section{BIBLIOGRAFI}

Demiarti, M., \& Utami, F. S. (2017). FaktorFaktor Yang Mempengaruhi Ketuban Pecah Dini Di Rsu Pku Muhammadiyah Bantultahun 2016.

Huda, N., Sulastri, S. K., \& Kp, S. E. S. (2013). Faktor-Faktor Yang 
Mempengaruhi Ketuban Pecah Dini Di Rs Pku Muhammadiyah Surakarta. Universitas Muhammadiyah Surakarta.

Isnaini, N. (2015). Karakteristik Penyebab Terjadinya Ketuban Pecah Dini Di Rsud Dr. H. Abdul Moeloek Provinsi Lampung. Holistik Jurnal Kesehatan, 9(4).

Lapau, B. (2012). Metode Penelitian Kesehatan, Yayasan Pustaka Obor Indonesia. Jakarta.

Legawati. (2018). Determinasi Kejadian Kpd Ruang Cempaka. Jurnal Kebidanan. Vol 3 (2), 95-105.

Leihitu. (2015). Masalah Kehamilan Dan Persalinan. Jakarta: Rineka Cipta.

Luwarsih, H. W., \& Ruhyana, R. (2014). Analisis Faktor-Faktor Yang Berhubungan Dengan Jenis Persalinan Pada Ibu Hamil Di Puskesmas Temon I Kulon Progo. Stikes'aisyiyah Yogyakarta.

Manuaba, I. B. G. (2010). Ilmu Kebidanan, Penyakit Kandungan Dan Keluarga Berencana. Jakarta: Egc, 15, 157.

Meliati, L. (2018). Analisis Faktor-Faktor Yang Berhubungan Dengan Kejadian Persalinan Prematur Di Rsup Ntb Tahun 2013. Jurnal Kesehatan Prima, 8(2), 1298-1307.

Notoatmdojo. (2014). Metodelogi Penelitian Kesehatan. Jakarta; Rineka Cipta.

Nugroho, A. (2010). Rekayasa Perangkat Lunak Berorientasi Objek Dengan Metode Usdp. Penerbit Andi.

Prastuti, A. (2016). Perbanndingan Mordibitas Perinatal Pada Kpd > 18jam Dan >18 Jam. Jurnal Kebidanan. Vol 4 (1), 31-35.

Prawirohardjo, S. \& Wiknjosastro, H. (2014). Ilmu Kandungan, Jakarta, Pt Bina Pustaka Sarwono Prawirohardjo.
Puspitasari, R. N. (2019). Korelasi Karakteristik Dengan Penyebab Ketuban Pecah Dini Pada Ibu Bersalin Di Rsud Denisa Gresik. Indonesian Journal For Health Sciences, 3(1), 24-32.

Ridwan, M., \& Herlina, H. (2017). Hubungan Kehamilan Ganda Dan Kelainan Letak Janin Dengan Kejadian Ketuban Pecah Dini Di Rsud Demang Sepulau Raya Lampung Tengah. Jurnal Kesehatan Metro Sai Wawai, 7(2), 43-49.

Rohmawati, N., \& Wijayanti, Y. (2018). Ketuban Pecah Dini Di Rumah Sakit Umum Daerah Ungaran. Higeia (Journal Of Public Health Research And Development), 2(1), 23-32.

Rosmiarti. (2016). Asuhan Kebidanan 4 (Patologi). Jakarta : Cv. Trans Info Media.

Tahir, L. (2014). Hubungan Panggul Sempit Dengan Partus Lama Di Ruang Bersalin Rsud Surabaya. Jurnal Kebidanan. Vol 5 No 3.

Winkjosastro. (2012). Ilmu Kebidanan. Jakarta: Egc. 